University of Wollongong

Research Online

Faculty of Engineering - Papers (Archive)

Faculty of Engineering and Information

Sciences

$1-1-2011$

\title{
Effects of membrane fouling and scaling on boron rejection by
} nanofiltration and reverse osmosis membranes

Kha Tu

University of Wollongong, Ikt883@uowmail.edu.au

Allan Chivas

University of Wollongong, toschi@uow.edu.au

Long Nghiem

University of Wollongong, longn@uow.edu.au

Follow this and additional works at: https://ro.uow.edu.au/engpapers

Part of the Engineering Commons

https://ro.uow.edu.au/engpapers/2924

\section{Recommended Citation}

Tu, Kha; Chivas, Allan; and Nghiem, Long: Effects of membrane fouling and scaling on boron rejection by nanofiltration and reverse osmosis membranes 2011, 269-277.

https://ro.uow.edu.au/engpapers/2924

Research Online is the open access institutional repository for the University of Wollongong. For further information contact the UOW Library: research-pubs@uow.edu.au 


\title{
Effects of membrane fouling and scaling on boron rejection by nanofiltration and reverse osmosis membranes
}

\author{
Revised Manuscript Submitted to
}

Desalination

May 2011

\begin{abstract}
Kha L. Tu ${ }^{1}$, Allan R. Chivas ${ }^{2}$ and Long D. Nghiem ${ }^{1, *}$
${ }^{1}$ Strategic Water Infrastructure Laboratory and GeoQuEST Research Centre

School of Civil Mining and Environmental Engineering University of Wollongong, NSW 2522, Australia

${ }^{2}$ GeoQuEST Research Centre, School of Earth \& Environmental Sciences University of Wollongong, NSW 2522, Australia
\end{abstract}

\footnotetext{
* Corresponding author: Long Duc Nghiem, Email: longn@uow.edu.au, Ph +61 242214590
} 


\begin{abstract}
The effects of membrane fouling on the performance of nanofiltration and reverse osmosis membranes with respect to boron rejection and permeate flux were investigated in this study. A nanofiltration (NF270) membrane and a reverse osmosis (BW30) membrane were used in this investigation. Four typical membrane fouling conditions were simulated under controlled laboratory conditions in a cross-flow membrane system using four model foulants including humic acid, sodium alginate, colloidal silica and $\mathrm{CaSO}_{4}$. Among these model foulants, humic acid was found to increase boron rejection whereas the other foulants led to a decrease in boron rejection. Properties of foulants were found to be an important factor that determined the transport of boron through the fouling layer. Results reported in this study also indicate that the extent of flux decline caused by different model foulants differed substantially from one another. The impact of membrane fouling on permeate flux decline was found to be dependent on the initial permeate flux and hydrophobicity of the foulant. On the other hand, membrane scaling was found to be governed by the salt rejection efficiency of the membrane. Cake-enhanced concentration polarisation appears to be a major mechanism that affects boron rejection efficiency of fouled membranes.
\end{abstract}

Keywords: boron, cake-enhanced concentration polarisation, fouling, scaling, nanofiltration, reverse osmosis.

\title{
1. Introduction
}

The rejection of boron by nanofiltration (NF) and reverse osmosis (RO) membranes has been extensively investigated in recent years due to a growing interest in seawater desalination to supplement potable water supply [1-2]. However, most studies currently available in the open literature focus on the rejection of boron under virgin membrane conditions. A notable exception is a study by Huertas et al. [3] who reported a significant decrease in boron rejection by NF/RO membranes under biologically fouled conditions. This observation was later confirmed by a mathematical model developed by Oh et al. [4]. Given that membrane fouling is inevitable for any membrane desalination plant, it is essential to investigate the boron removal efficiency under fouled membrane conditions.

Membrane fouling can substantially decrease permeability, increase operational cost and shorten membrane life [5-8]. Organic fouling typically exhibits a range of behaviour due to 
the complex interactions between chemical functional groups of organic foulants and those of the polymeric membrane skin layer [9-11]. Alginate, a polysaccharide compound, was reported to be able to block the "valleys" made by roughness on the membrane surface, and also form a dense cake layer composed of cross-links between carboxylate functional groups on neighbouring alginate molecules by calcium ions bridging [12]. Therefore, severe flux decline is usually observed when the membrane is fouled by alginate substances. Physiochemical properties of membranes also play an important role in the extent of organic fouling. A study by Nghiem and Hawkes [13] revealed that permeate flux decline due to membrane fouling would be more severe with membranes having larger pore size. The authors also argued that pore blocking was the predominant fouling mechanism at the first stage of fouling, and the latter stage is governed by cake-enhanced mechanism. Several studies found that higher negative zeta potential and hydrophilicity of the membrane surface should lead to less fouling by organic macromolecules due to higher electrostatic repulsion and lower hydrophobic interactions between the foulant and membrane surface $[12,14]$. In addition, it is reported that solution conditions such as $\mathrm{pH}$ and ionic strength also contribute to the extent of membrane fouling by organic molecules [7, 14-17].

The impact of colloidal fouling on permeate flux decline has been extensively reported in the literature [8, 18-20]. Cohen and Probstein [21] found a linear connection between permeate flux decline and foulant layer thickness during the initial stages of fouling. This observation was attributed to the enhanced osmotic pressure caused by colloidal cake layer which obstructs the back diffusion of salt ions from the membrane surface to the bulk solution [2224]. This phenomenon was also utilised to elucidate the increasing salt passage through the membrane which was usually observed when colloidal fouling occurred. Furthermore, Lee et al. [20] reported that the decrease in salt rejection of NF membranes was more severe than that of RO membranes because the cake layer could reduce the membrane charged exclusion which was more important in NF than RO membranes. The extent of colloidal deposition on the membrane surface was also found to be affected by properties of colloid (size and hydophobicity) [25] and of the membrane surface (membrane roughness and hydrophobicity) [26-28].

During the membrane filtration process, sparingly soluble salts such as $\mathrm{CaCO}_{3}$ and $\mathrm{CaSO}_{4}$ may become supersaturated and precipitate on the membrane surface to cause membrane scaling. According to Lee et al. [29], the flux decline in cross-flow NF could be attributed to 
not only surface crystallisation but also due to bulk crystallisation. In fact, in a similar study, Gilron and Hasson [30] attributed bulk rather than surface crystallisation to the observed flux decline. Pervov [31] described the scaling process as the crystal formation took place in the bulk solution due to strong oversaturation in the deadlocks, and then the crystals approached and precipitated on the membrane surface. The impact of membrane scaling on salt rejection has not been extensively investigated. Scaling of divalent cations such as $\mathrm{Ca}^{2+}$ may induce more positive charge to the membrane surface, and consequently reduce the rejection of charge solutes [32].

This study aims to investigate the effects of membrane fouling on the rejection of boron by NF/RO membranes. Four typical membrane fouling conditions were simulated under controlled chemical and physical conditions in a laboratory-scale cross-flow membrane system using four model foulants. Membrane fouling was systematically related to the membrane and foulant characteristics. The separation behaviours of boron under different solution $\mathrm{pH}$ were subsequently described and discussed in detail.

\section{Materials and methods}

\subsection{Chemicals and reagents}

Unless otherwise stated, all experiments were conducted based on an electrolyte background that includes $\mathrm{NaCl}, \mathrm{CaCl}_{2}$, and $\mathrm{NaHCO}_{3}$ at concentrations of $10 \mathrm{mM}, 1 \mathrm{mM}$, and $1 \mathrm{mM}$, respectively. Boron in the form of boric acid $\left(\mathrm{H}_{3} \mathrm{BO}_{3}\right)$ was spiked into the feed solution at a level of $0.43 \mathrm{mM}$ (or $4.6 \mathrm{mgL}^{-1}$ as boron) to represent the average boron concentration in seawater [33]. $\mathrm{NaHCO}_{3}$ was used as a buffer reagent. Adjustment of the feed water $\mathrm{pH}$ was carried out by adding an appropriate volume of $1 \mathrm{M} \mathrm{NaOH}$ or $1 \mathrm{M} \mathrm{HCl}$. Humic acid, sodium alginate, colloidal silica and $\mathrm{CaSO}_{4}$ were used as model foulants and scalant to simulate organic substance, colloidal matter, and inorganic divalent salt that are ubiquitous in natural water sources. These model foulants were purchased from Sigma-Aldrich (Castle Hill, Australia) except $\mathrm{CaSO}_{4}$ which was purchased from Ajax Chemicals (Auburn, Australia). The Aldrich humic acid and alginate have molecular weights in the range of $12-80 \mathrm{kDa}$ and 4 - $100 \mathrm{kDa}$, respectively. Colloidal silica (Ludox HS30) is monodispersed colloid particles which are negatively charged at neutral or high $\mathrm{pH}$ rendering them somewhat hydrophilic. The colloidal particle has an average hydrodynamic diameter of $18 \mathrm{~nm}$ [28] and was supplied 
at $30 \%$ weight suspension in water and was stored at $4{ }^{\circ} \mathrm{C}$. Suprapur grade nitric acid from Merck Co. (Darmstad, Germany) was used for dilution and sample preparation prior to inductively-coupled plasma mass spectrometry (ICP-MS) analysis. All other chemicals used in this study are of analytical grade.

\subsection{Membrane filtration system and experimental protocol}

A NF membrane (NF270) and a RO membrane (BW30) were used. Both membranes were supplied by Dow FilmTec ${ }^{\mathrm{TM}}$ (Minneapolis, MN, USA) as flat sheet samples and were stored dry.

A laboratory-scale NF/RO filtration system equipped with a cross-flow stainless steel membrane cell was used in this study. The cell could hold a flat sheet membrane sample with an effective membrane area of $40 \mathrm{~cm}^{2}(4 \mathrm{~cm} \times 10 \mathrm{~cm})$. The channel height of the cell was 2 mm. The unit utilized a Hydra-Cell pump (Wanner Engineering Inc., Minneapolis, MN) capable of providing pressures up to $6,800 \mathrm{kPa}$ and a flow rate of $4.2 \mathrm{Lmin}^{-1}$. Feed pressure and cross-flow velocity were controlled by a bypass valve and a back-pressure regulator. The temperature of the test solution was kept constant using a chiller/heater (Neslab RTE 7) equipped with a stainless steel heat exchanger coil, which was submerged directly into a stainless steel reservoir. Permeate flow was measured by a digital flow meter (Optiflow 1000, Agilent Technologies, Palo Alto, CA) connected to a computer, and the cross-flow rate was monitored by a rotameter. Permeate and retentate flows were recycled back to the feed reservoir.

The fouling and subsequent rejection test protocols were performed in three stages: compacting, fouling development, and rejection test. At first, the membrane was compacted using $9 \mathrm{~L}$ deionized water at a pressure of approximately $500 \mathrm{kPa}$ higher than the rejection test pressure. Membrane compaction was conducted for at least $1 \mathrm{~h}$ until a stable baseline flux was obtained. The electrolyte solution was then added to the feed reservoir, and made up to the total feed volume of $10 \mathrm{~L}$. The fouling layer was then allowed to develop by dosing one of the nominated model foulants (humic acid, sodium alginate, and colloidal silica) at a concentration of $20 \mathrm{mgL}^{-1}$ (in total mass). Membrane scaling was simulated by adding $\mathrm{CaSO}_{4}$ to the electrolyte solution to make up $1 \mathrm{gL}^{-1}$ of $\mathrm{CaSO}_{4}$. The permeate flux was then adjusted to be $84 \mathrm{Lm}^{-2} \mathrm{~h}^{-1}$ for NF270 membrane and $60 \mathrm{Lm}^{-2} \mathrm{~h}^{-1}$ for the BW30 membrane. The fouling development was carried out for $18 \mathrm{~h}$ and the feed solution $\mathrm{pH}$ was kept at 8.2. After the 
fouling development step, boric acid was spiked to the feed solution at the concentration of $0.43 \mathrm{mM}$. The cross-flow velocity and permeate flux were then adjusted to be $30.4 \mathrm{cms}^{-1}$ and $40 \mathrm{Lm}^{-2} \mathrm{~h}^{-1}$, respectively. The temperature of the feed solution was kept constant at $20 \pm 0.1$ ${ }^{\circ} \mathrm{C}$ during the experiment. To assess the impact of solution $\mathrm{pH}$ on the rejection of boron, the solution $\mathrm{pH}$ was raised to 11 by adding an appropriate volume of $1 \mathrm{M} \mathrm{NaOH}$, and then the $\mathrm{pH}$ was incrementally dropped to $\mathrm{pH} 6$ by adding $1 \mathrm{M} \mathrm{HCl}$. At each $\mathrm{pH}$ value, the system was stablised for $1 \mathrm{~h}$ prior to the collection of feed and permeate samples for electrical conductivity and ICP-MS analysis. The system was operated under a full recirculation mode where both permeate and retentate were re-circulated to the feed tank. The permeate flux was kept constant during the experiment to minimize the effect of flux on rejection.

\subsection{Zeta potential measurement}

The zeta potential of the membrane surface was measured by a SurPASS electrokinetic analyser (Anton Paar GmbH, Graz, Austria). The zeta potential of the membrane surface was calculated from the measured streaming potential using the Fairbrother-Mastin approach [34]. All streaming potential measurements were conducted in the background electrolyte which was previously described in Section 2.1. $\mathrm{HCl}(1 \mathrm{M})$ and $\mathrm{KOH}(1 \mathrm{M})$ solutions were used to adjust the $\mathrm{pH}$ by manual titration. The test solution was used to thoroughly flush the cell prior to the $\mathrm{pH}$ adjustment for each measurement. All streaming potential measurements were performed at room temperature of approximately $25{ }^{\circ} \mathrm{C}$, which was monitored by the temperature probe of the instrument.

\subsection{Surface roughness morphology}

Surface roughness of the membranes was characterised by a multimode atomic force microscope (AFM) (Digital Instruments, Santa Barbara, CA). Imaging was taken in air in tapping mode operation using an oxide sharpened SiN probe. The membrane average surface roughness was determined in triplicate mode by AFM image analysis over a $2 \mu \mathrm{m} \times 2 \mu \mathrm{m}$ surface area.

\subsection{Contact angle measurement}

Contact angle measurements were conducted by a Rame-Hart Goniometer (Model 250, Rame-Hart, Netcong, NJ) using the standard sessile drop method. Milli-Q water was used as the reference solvent. The membranes were dried in the air before the measurements. Contact 
angles on both sides of the droplet were measured. At least 5 droplets on each membrane sample were measured, and twenty counts of each droplet were recorded.

\subsection{Scanning electron microscope}

The clean and fouled membranes were visually characterised with a JSM-6490LA (JEOL Japan) scanning electron microscope (SEM). Before introduction to the electron beam, the membrane sample was coated with a thin layer of carbon using a carbon sputter. SEM images were taken at a magnification of 2,500 fold at $20 \mathrm{kV}$. The elemental analysis was determined using an integrated energy-dispersive spectrometer (EDS).

\subsection{Analytical methods}

The concentrations of boron, sodium and calcium were analysed using an Agilent 7500CS ICP-MS (Agilent Technologies, Wilmington, DE, USA). A lithium internal standard (BDH Spectrosol, Poole, U.K.) was spiked to all samples at the concentration of $40 \mu \mathrm{gL}^{-1}$. Sample dilution was carried out with 5\% Suprapur nitric acid with a dilution factor of up to 20 . To avoid contamination, all apparatus related to preparing samples were plastic materials, and were soaked in 5\% Suprapur nitric acid for at least $24 \mathrm{~h}$ before being used. Calibration was conducted prior to each batch of analysis. The linear regression coefficients for all calibration curves were greater than 0.99 for all elements. Prior to each batch of analyses, the ICP-MS was tuned by a multi-element tuning solution that contained $10 \mu \mathrm{gL}^{-1}$ of $\mathrm{Li}, \mathrm{Y}, \mathrm{Ce}, \mathrm{Tl}$ and Co. Each analysis was conducted in triplicate and the variation was always less than 5\%. Conductivity and $\mathrm{pH}$ were measured using an Orion 4-Star Plus $\mathrm{pH} /$ conductivity meter (Thermo Scientific, Beverly, MA).

\section{Results and discussion}

\subsection{Characterization of virgin and fouled membranes}

According to the manufacturer, the two membranes used in this study are made of an ultra thin polyamide skin layer on top of a microporous polysulfone supporting layer. The former governs the separation characteristics of the membrane whereas the later provides mechanical strength to the membrane. The NF270 membrane has an average pore diameter of $0.84 \mathrm{~nm}$ [35], whereas the BW30 is considered to have a non-porous active skin layer. The rejection of typical salts (sodium and calcium) and pure water permeability of the membranes directly 
correspond to the membrane pore sizes (Table 1). The virgin NF270 membrane has a very smooth surface with a surface roughness of $4.1 \mathrm{~nm}$ compared to that of the virgin BW30 membrane with a surface roughness of $62.6 \mathrm{~nm}$ (Table 1). The high surface roughness of the BW30 membrane could render this membrane more susceptible to fouling because foulant particles could accumulate in the valleys on the membrane surface due to higher local flux over valley regions [27]. Although the contact angle (which measures the hydrophobicity of the membrane surface) does not directly affect the rejection of solute, this parameter can determine the transport of water through membranes which governs the overall rejection of a membrane system [36].

Table 1. Properties of the membranes used in this study.

\begin{tabular}{lllllll}
\hline Membrane & $\begin{array}{l}\text { Average pore } \\
\text { diameter } \\
(\mathrm{nm})\end{array}$ & $\begin{array}{l}\mathrm{Na}^{+} \\
\text {rejection } \\
(\%)\end{array}$ & $\begin{array}{l}\mathrm{Ca}^{2+} \\
\text { rejection } \\
(\%)\end{array}$ & $\begin{array}{l}\text { Pure water } \\
\text { permeability } \\
\left(\mathrm{Lm}^{-2} \mathrm{~h}^{-1} \mathrm{bar}^{-1}\right)\end{array}$ & $\begin{array}{l}\text { Contact } \\
\text { angle } \\
(\circ)\end{array}$ & $\begin{array}{l}\text { Surface } \\
\text { roughness }\end{array}$ \\
$(\mathrm{nm})$
\end{tabular}

${ }^{\mathrm{a}} \operatorname{Ref}[35]$.

${ }^{\mathrm{b}}$ Rejection data were recorded at $\mathrm{pH} 8$.

${ }^{\mathrm{c}}$ Scanning area $2 \mu \mathrm{m} \times 2 \mu \mathrm{m}$.

Because the polyamide layer that makes up the membrane active skin contains both carboxylic and amine functional groups that can ionize in an aqueous solution [14], the membrane surface zeta potential can vary as a function of the solution chemistry, such as $\mathrm{pH}$ and ionic strength. Schäfer et al. [37] reported that a more negative membrane zeta potential could lead to a higher salt rejection due to an enhanced electrostatic interaction between the negatively charged membrane surface and charged solutes. The membranes selected in this study have negative charge in the investigated $\mathrm{pH}$ range (Figure 1). In addition, their negative surface charge density increases as the solution $\mathrm{pH}$ increases. This phenomenon suggests that electrostatic interaction can be an important rejection mechanism of charged solutes, particularly for the NF membrane. 


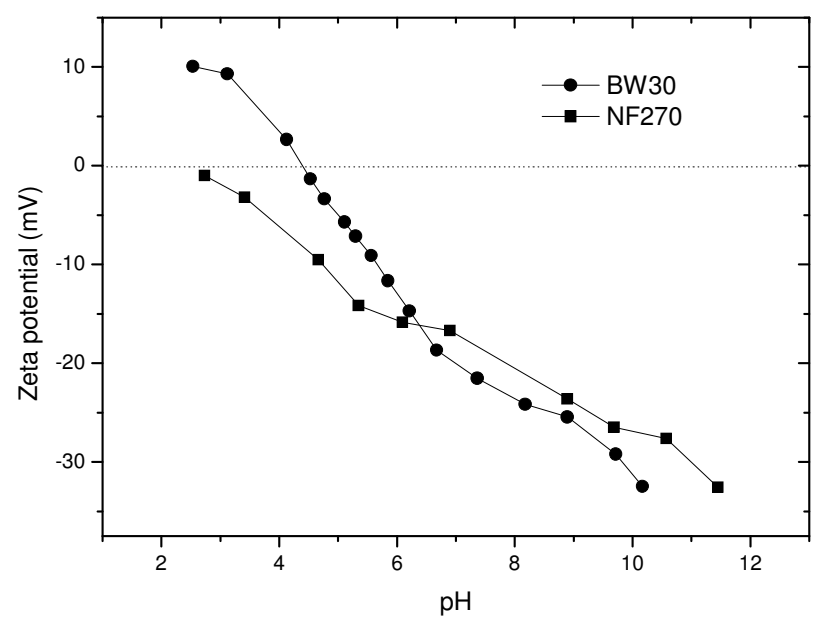

Figure 1. Zeta potential of the selected membranes (measured at $25^{\circ} \mathrm{C}$, in a background electrolyte solution containing $\mathrm{NaCl}, \mathrm{CaCl}_{2}$, and $\mathrm{NaHCO}_{3}$ at concentrations of $10 \mathrm{mM}, 1$ $\mathrm{mM}$, and $1 \mathrm{mM}$, repectively; $\mathrm{pH}$ was adjusted using $\mathrm{HCl}$ or $\mathrm{KOH}$ solutions).

The contact angle data which reflect the hydrophobicity of the virgin and fouled membranes are illustrated in Figure 2. The virgin BW30 membrane appeared to be more hydrophobic than the virgin NF270 membrane. Higher hydrophobicity could make the BW30 membrane become vulnerable to fouling due to hydrophobic interaction between membrane surface and hydrophobic foulants. However, despite having different hydrophobicity in virgin condition, these two membranes showed very similar contact angle values once they were fouled by the same foulant (Figure 2). This observation suggests that hydrophobicity, and probably other physiochemical properties of the fouled membranes are governed by the fouling layer rather than the aromatic polyamide active layer of the membrane surface. 

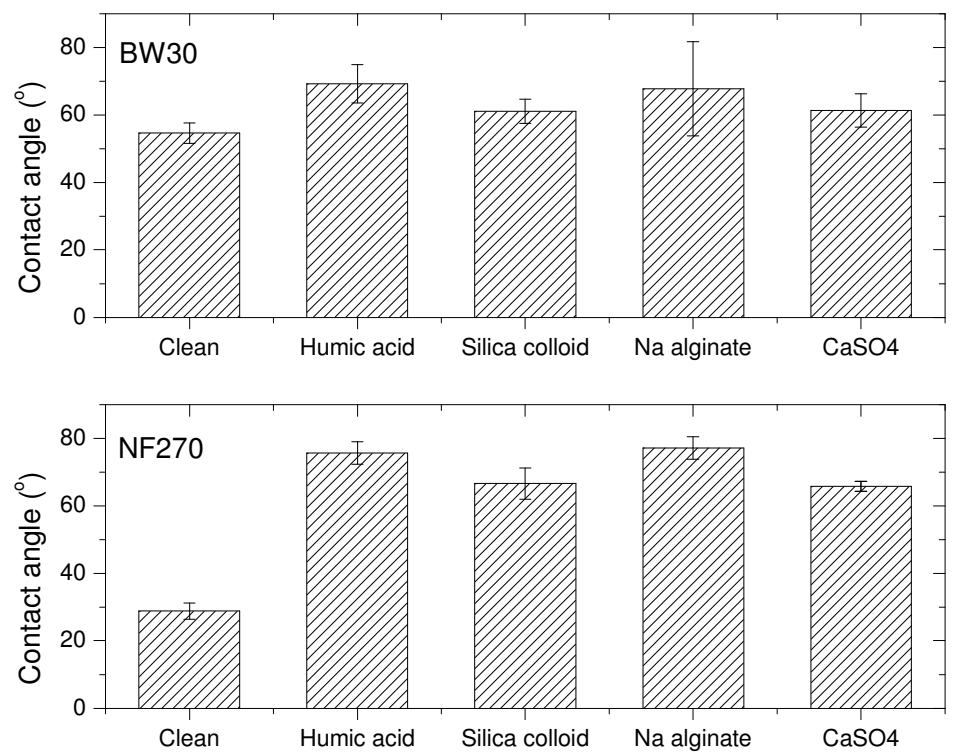

Figure 2. Contact angle values of the investigated clean and fouled membranes. Milli-Q water was used as the reference solvent. The error bars show the standard deviation of five replicate measurements.

SEM analysis confirmed that at the completion of the fouling development stage, the membrane surface was completely covered by the fouling layer (Figure 3). Because the model foulants are significantly larger than the pore size of the NF270 membrane, permeation of the organic and silica colloids through the membrane did not occur as could be confirmed by the low turbidity of the permeate samples. Surface morphology and composition of the virgin membrane (Figure 3a) differed distinctively from that of the fouled membranes (Figure 3b, 3c, 3d, 3e). Humic acid, alginate and colloidal silica formed a dense and uniform cake layer on the membrane surface as a result of hydrophobic interactions between the foulants and membrane surfaces. On the other hand, $\mathrm{CaSO}_{4}$ crystallised and precipitated on the membrane surface to establish a spongy and coarse layer that highlighted the foulant-foulant interactions. This $\mathrm{CaSO}_{4}$ scaling layer is expected to affect the membrane permeate flux by a lesser extent than that by the humic, alginate and colloidal silica foulants. Elementary compositions of the fouling layer obtained from qualitative EDS analysis were consistent with key signature elements of the corresponding foulants (Figure 3). In addition to the model foulants, carbon, oxygen and sulfur were parts of the membrane polymeric composition and thus were detected in all samples, including the virgin membrane (Figure 3a). A high level of calcium was found in the alginate fouling layer (Figure 3c). This result is consistent with 
previous studies that calcium could make cross-links with alginate molecules and accumulate in the alginate fouling layer [12]. Silica was the most abundant element of the colloidal silica fouling layer (Figure 3d). Similarly, the $\mathrm{CaSO}_{4}$ scaling could also be confirmed by the dominant presence of sulfur and calcium on the membrane surface (Figure 3e).

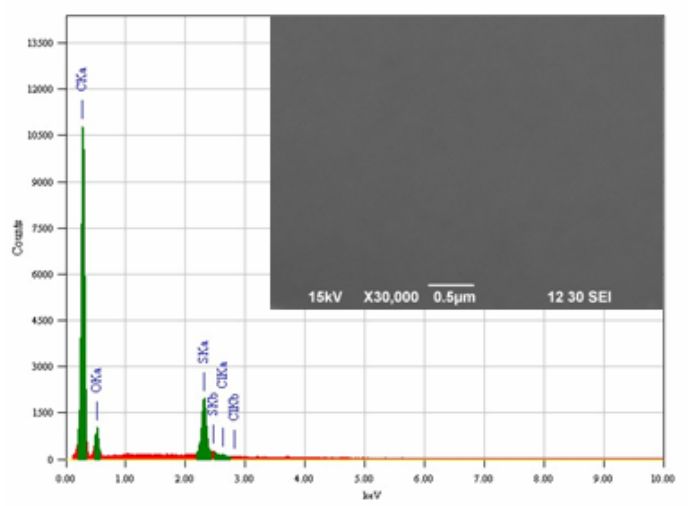

(a) Virgin NF270 membrane
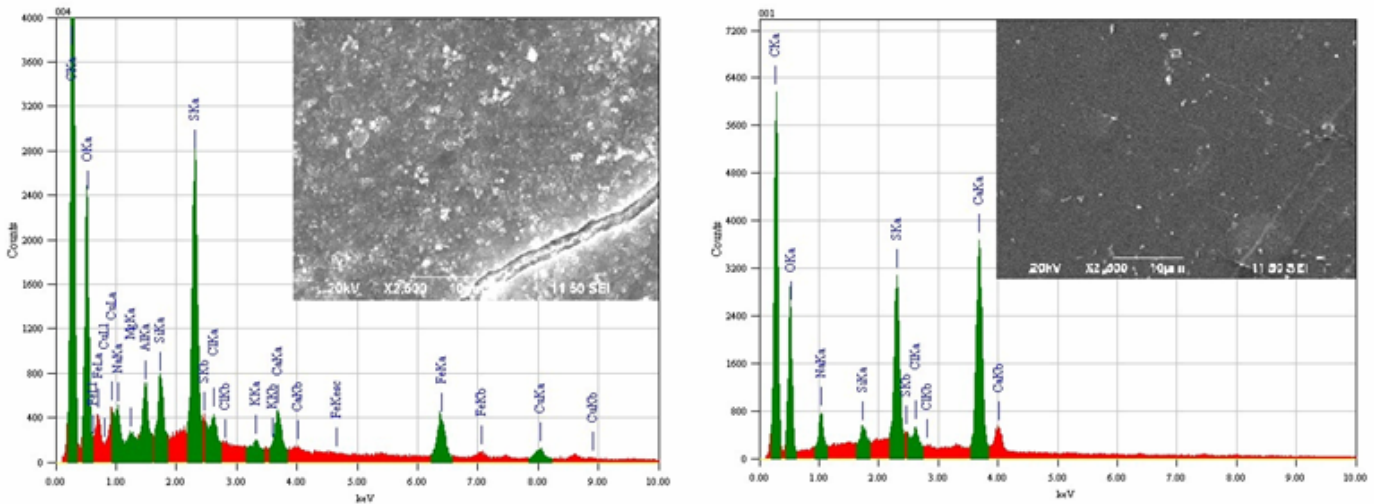

(b) Membrane fouled by humic acid

(c) Membrane fouled by sodium alginate
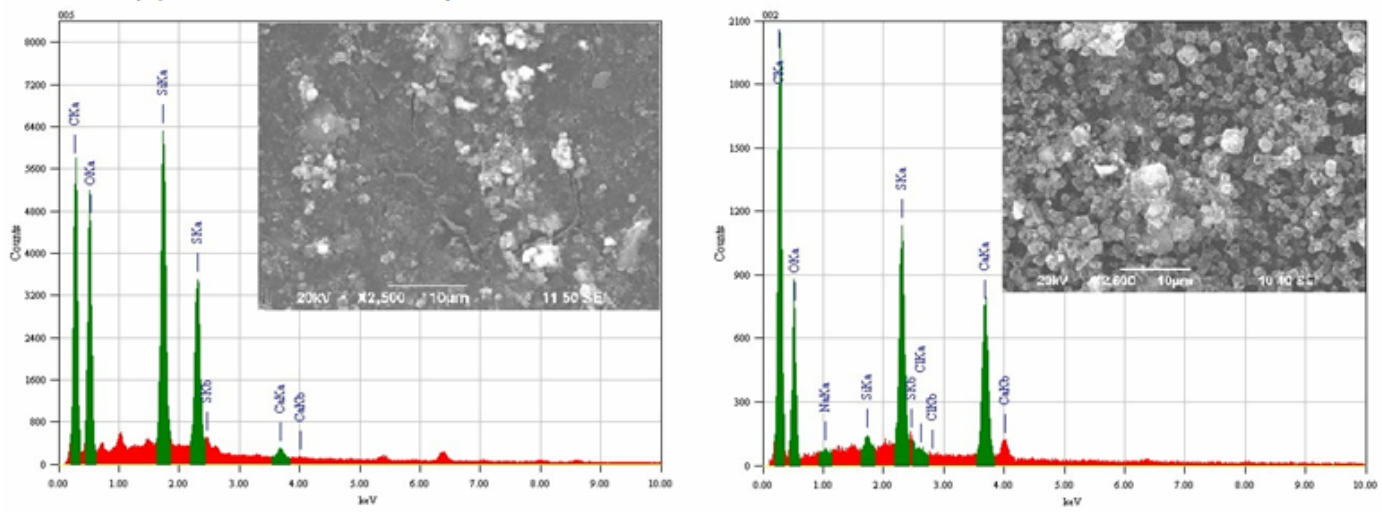

(d) Membrane fouled by colloidal silica

(e) Membrane scaled by $\mathrm{CaSO}_{4}$ scaling

Figure 3. SEM images and EDS data of the (a) virgin NF270 membrane, membrane surfaces fouled by (b) humic acid, (c) sodium alginate, (d) colloidal silica, and (e) $\mathrm{CaSO}_{4}$ scaling. The membrane samples were coated with a thin layer of carbon using a carbon sputter. 


\subsection{Membrane fouling behaviour}

Figure 4 shows the alteration of permeate flux as a function of fouling development time (Figure 4a) and as a function of accumulated mass of foulant on the membrane surface (Figure $4 \mathrm{~b}$ ). The latter was calculated based on a simple mass-balance assuming that the foulant was completely retained by the membrane and that tangential transport of the foulant away from the membrane surface was negligible. Membrane fouling of the BW30 was less severe in comparison to that of the NF270 membrane, with $\mathrm{CaSO}_{4}$ being the only exception (Figure 4). This proportional behaviour between the initial permeate flux decline rate and membrane pore size was reported previously [13]. The greater membrane fouling observed with the NF270 membrane could be attributed to the higher operational initial permeate flux $\left(84 \mathrm{Lm}^{-2} \mathrm{~h}^{-1}\right)$ in comparison to that $\left(60 \mathrm{Lm}^{-2} \mathrm{~h}^{-1}\right)$ of the BW30 membrane. The higher initial permeate flux introduced more foulant to the membrane surface, and subsequently encouraged fouling on the NF270 membrane (Figure 4b). It is noteworthy that the virgin NF270 membrane possesses a lesser surface roughness, lower hydrophobicity (Table 1) and higher negative zeta potential (Figure 1) which could subsequently lead to lower fouling potential compared to the BW30 membrane. The data reported here (Figure 4) suggest that the impact of surface roughness, hydrophobicity and zeta potential was overwhelmed by the high initial permeate flux that makes the NF270 membrane more susceptible to fouling compared to the BW30 membrane. On the other hand, the BW30 membrane was more severely influenced by $\mathrm{CaSO}_{4}$ scaling than the NF270 membrane (Figure 4). In this case, higher salt rejection efficiency of the BW30 membrane compared to that of the NF270 membrane generated a greater concentration polarisation at the membrane surface. Consequently, membrane scaling caused by the precipitation of $\mathrm{CaSO}_{4}$ was more severe for the BW30 than for the NF270 membrane. In addition, Figure 4b shows that at the same accumulated masses, different foulants caused different extent of flux decrease. This implies that the properties of foulants play the key role in governing the fouling extent. 

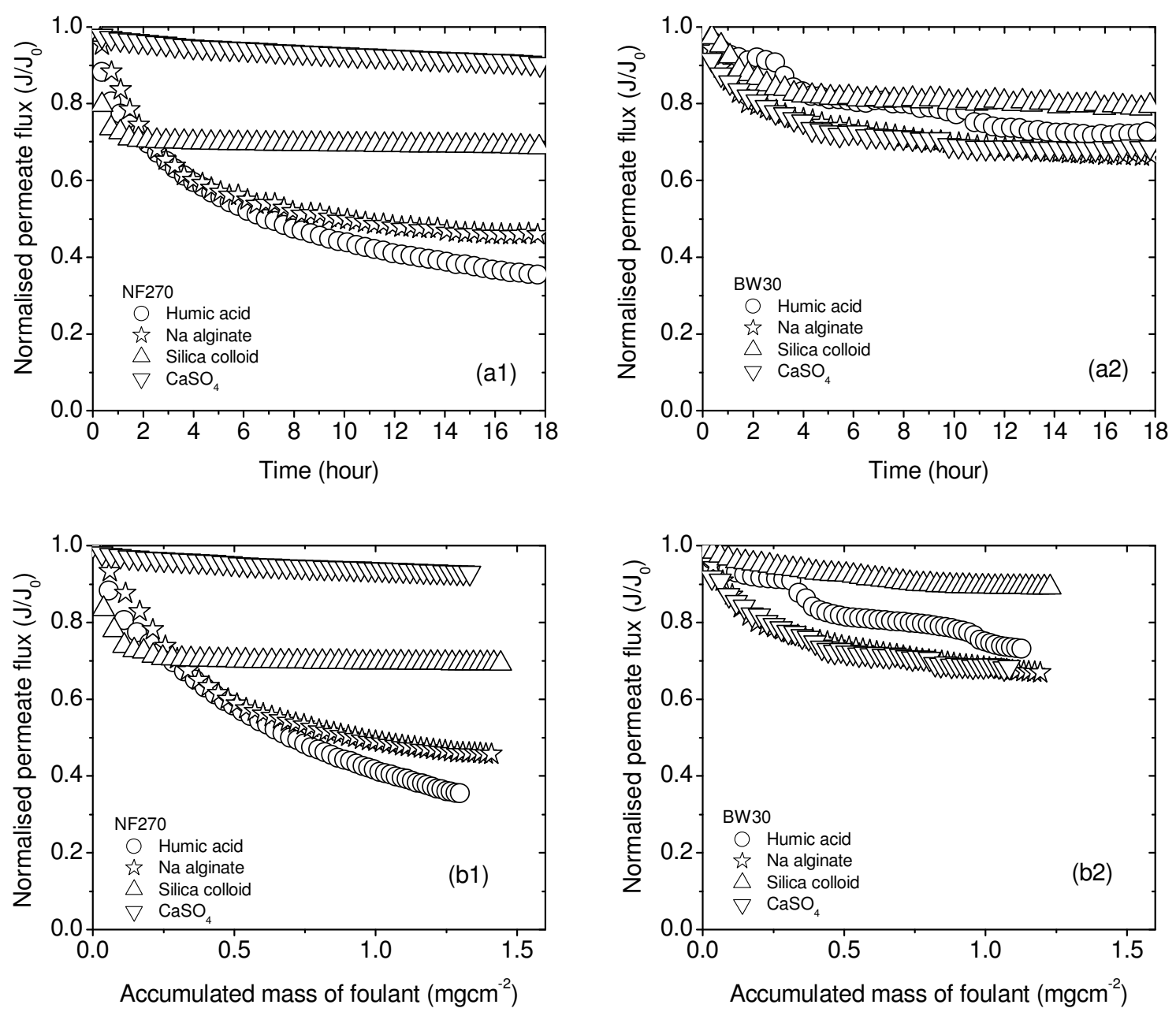

Figure 4. Normalised permeate flux as a function of (a) time and (b) accumulated mass of foulant on the membrane surface. Initial permeate flux: $84 \mathrm{Lm}^{-2} \mathrm{~h}^{-1}$ for NF270 membrane and $60 \mathrm{Lm}^{-2} \mathrm{~h}^{-1}$ for BW30 membrane, respectively. Feed solution: $10 \mathrm{mM} \mathrm{NaCl}, 1 \mathrm{mM} \mathrm{CaCl}_{2}, 1$ $\mathrm{mM} \mathrm{NaHCO} 3$, and $20 \mathrm{mgL}^{-1}$ of each foulant, except $\mathrm{CaSO}_{4}$ was $1 \mathrm{gL}^{-1}$. For data presentation purposes, the accumulated mass of $\mathrm{CaSO}_{4}$ shown in the figure has been divided by 50 .

Membrane fouling can occur in two successive stages where foulant-membrane interactions determine fouling mechanisms at the first stage, and the latter stage is governed by foulantfoulant interactions $[12-13,38]$. The rapid decrease in permeate flux at the first stage implied that foulant-membrane interactions played a dominant role in fouling development. This is the case of the NF270 membranes fouled by humic acid, sodium alginate and colloidal silica (Figure 4-1). A very sharp and substantial flux drop was observed with these fouled membranes within the first hour, and then the decrease rate became noticeably lower, even inconsiderable in case of the colloidal silica fouling. The foulant-membrane interactions 
could be the hydrophobic interaction between the organic foulants and the membrane surface $[12,14]$ and the clogging impact of the foulant particles to the valleys on the membrane surface [12]. This phenomenon seemed not occur at the $\mathrm{CaSO}_{4}$ scaling membrane because of the large size of the $\mathrm{CaSO}_{4}$ crystals. The later stage of fouling development, which is governed by foulant-foulant interactions, caused less effect on permeate flux decline. In particular, the presence of $\mathrm{Ca}^{2+}$ in the feed solution could cause severe impact on the flux decline because $\mathrm{Ca}^{2+}$ could bridge carboxylate functional groups on neighbouring alginate molecules and so make the fouling layer thicker and denser [10, 12, 39-40]. This finding is verified by the high level of calcium found in the fouling layer (Figure 3c). In general, cakeenhanced concentration polarisation may occur and reduce the permeate flux of all the fouled membranes. In this phenomenon, back diffusion of solutes at the membrane surface to bulk solution is hindered by the fouling layer, and results in a substantial increase in solute concentration at the membrane surface [23]. The increase in solute concentration led to an increase in osmotic pressure and subsequently a decrease in permeate flux [41].

\subsection{Effects of fouling and $\mathrm{pH}$ on the rejection of boron and salts}

Boron rejection by both virgin and fouled membranes was greatly affected by solution $\mathrm{pH}$ (Figure 5). An increase in the solution $\mathrm{pH}$ could substantially increase boron rejection by NF/RO membranes, and the NF270 membrane was more sensitive to this effect than the BW30 membrane (Figure 5). In particular, boron rejection by the NF270 membrane under both virgin and fouled conditions was negligible at $\mathrm{pH}$ lower than 8 , and the rejection increased up to $40-60 \%$ when the solution $\mathrm{pH}$ increased to 11 . As a notable exception, the humic acid fouled NF270 membrane showed a rejection value of almost $30 \%$ below pH 8 . This observation will be further discussed in a later section. On the other hand, boron rejection by the BW30 membrane in virgin and fouled conditions increased by only about $35 \%$ when the solution $\mathrm{pH}$ increased from 6 to 11 (Figure 5). Mechanisms governing boron rejection by virgin $\mathrm{NF} / \mathrm{RO}$ membranes have been elucidated in previous studies as size exclusion (at low $\mathrm{pH}$ ) and charged repulsion (at high $\mathrm{pH}$ ) [42-44]. The similar behaviour of the fouled and virgin membranes as solution $\mathrm{pH}$ increased (Figure 5) implied that mechanisms governing boron rejection by virgin membranes did not change substantially when the membranes were fouled, and therefore these mechanisms could be applied to explain boron rejection by fouled membranes. 


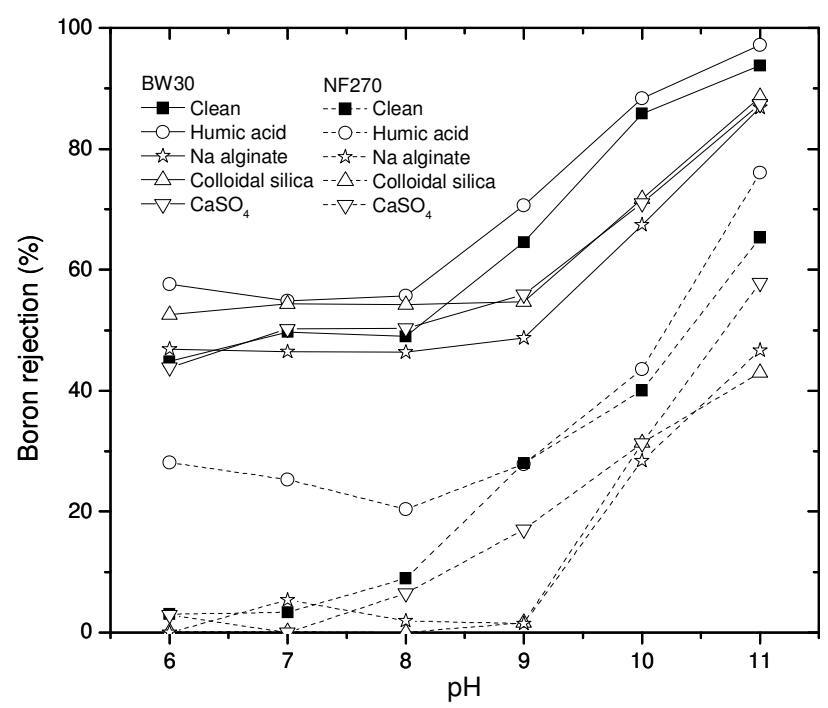

Figure 5. Boron rejection by virgin and fouled NF270 and BW30 membranes as a function of solution pH. Feed solution: $10 \mathrm{mM} \mathrm{NaCl}, 1 \mathrm{mM} \mathrm{CaCl}_{2}, 1 \mathrm{mM} \mathrm{NaHCO}_{3}, 0.43 \mathrm{mM} \mathrm{B}(\mathrm{OH})_{3}$ and $20 \mathrm{mgL}^{-1}$ of each foulant, except $\mathrm{CaSO}_{4}$ was $1 \mathrm{gL}^{-1}$; feed temperature $=20{ }^{\circ} \mathrm{C}$; permeate flux $=40 \mathrm{Lm}^{-2} \mathrm{~h}^{-1}$; cross flow velocity $=30.4 \mathrm{cms}^{-1}$.

Fouled membranes responded to changes in solution $\mathrm{pH}$ at a lower degree than virgin membranes (Figure 5). In other words, the fouling layer seemed to reduce the impact of solution $\mathrm{pH}$ on boron rejection. For example, when the solution $\mathrm{pH}$ increased from 6 to 11, boron rejection by the virgin NF270 membrane increased 65\%, whereas it was only approximately $45 \%$ for the membranes fouled by sodium alginate and by colloidal silica (Figure 5). In this case, the fouling layer acts as a physical barrier that shields the contact between the bulk solution and membrane surface. Consequently, the zeta potential and double-charged layer of the membrane would not be substantially affected by solution $\mathrm{pH}$ changes, and lower boron rejection attained by fouled membranes as a result. Indeed, Tang et al. [45] reported a constant zeta potential of the NF270 membrane fouled by Aldrich humic acid when solution $\mathrm{pH}$ varied in the range of 3.5 - 9.5. In addition, the colloidal silica and $\mathrm{CaSO}_{4}$ fouling layers could not only shield the contact between the membrane surface and the bulk solution, but also neutralise the membrane surface charge which explains the lower rejection of boron by membranes fouled by colloidal silica and $\mathrm{CaSO}_{4}$. The charged neutralisation feature of these two foulants has been reported in the literature [20,32]. On the other hand, solution $\mathrm{pH}$ changes affected boron rejection more apparently at the fouled NF270 than at the fouled BW30 membrane. Size exclusion was thought to be the dominant 
rejection mechanism of boron by the BW30 membrane and this rejection mechanism was not significantly affected by solution chemistry [42]. Indeed, the role of size exclusion and its relationship with solution $\mathrm{pH}$ apparently revealed in the rejection of conductivity and sodium (Figure 6). Conductivity and sodium rejection by the fouled NF270 membranes were almost invariable with increasing solution $\mathrm{pH}$, whereas their rejection by the virgin NF270 membrane significantly improved (Figure 6). Similar observations were reported by several previous studies [45-47].
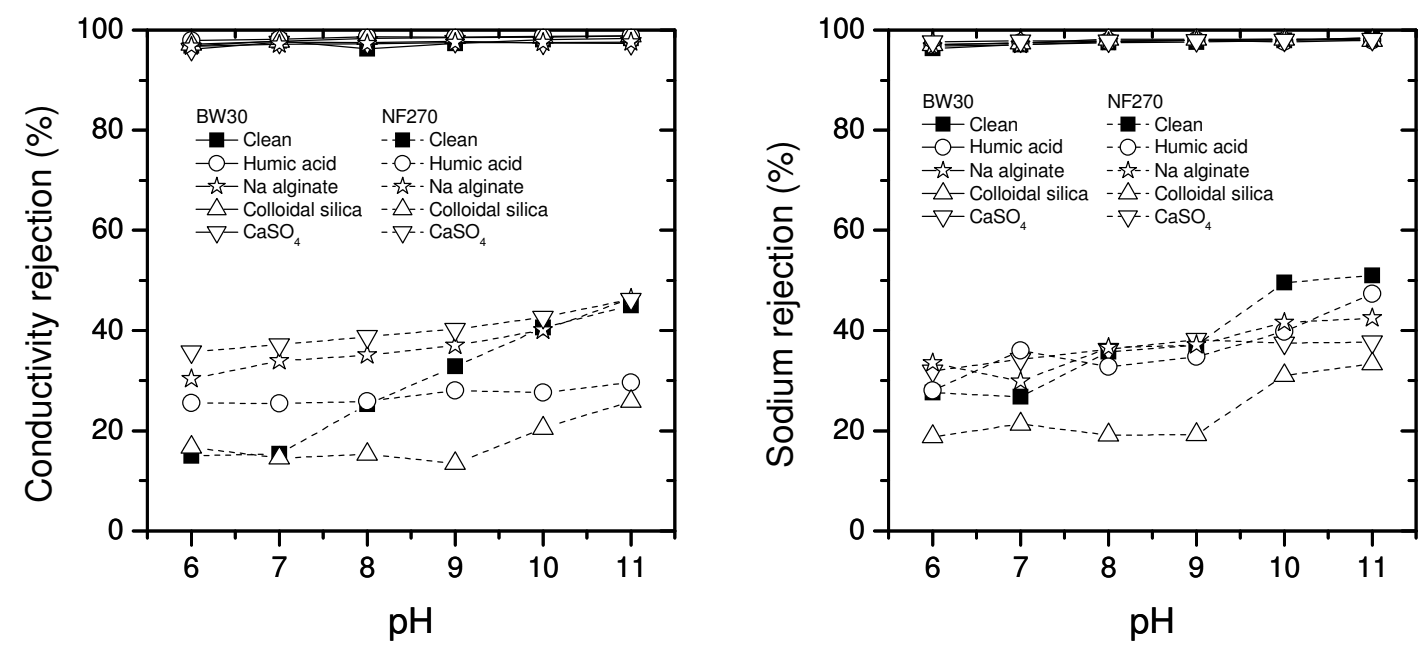

Figure 6. The rejection of conductivity and sodium by virgin and fouled NF270 and BW30 membranes as a function of solution $\mathrm{pH}$. Feed solution: $10 \mathrm{mM} \mathrm{NaCl}, 1 \mathrm{mM} \mathrm{CaCl} 2,1 \mathrm{mM}$ $\mathrm{NaHCO}_{3}, 0.43 \mathrm{mM} \mathrm{B}(\mathrm{OH})_{3}$ and $20 \mathrm{mgL}^{-1}$ of each foulant, except $\mathrm{CaSO}_{4}$ was $1 \mathrm{gL}^{-1}$; feed temperature $=20{ }^{\circ} \mathrm{C}$; permeate flux $=40 \mathrm{Lm}^{-2} \mathrm{~h}^{-1}$; cross flow velocity $=30.4 \mathrm{cms}^{-1}$.

Under high $\mathrm{pH}$ conditions, the difference in boron rejection by virgin and fouled membranes was apparent. The boron rejection efficiency of virgin membranes was considerably higher than that of the $\mathrm{CaSO}_{4}$, alginate and colloid-fouled membranes. One possible explanation for the lower boron rejection observed with the membranes fouled by sodium alginate, colloidal silica and $\mathrm{CaSO}_{4}$ under high $\mathrm{pH}$ conditions is the impact of cake-enhanced concentration polarisation caused by fouling layers. Cake-enhanced concentration polarisation has been extensively reported as a major cause of decrease in solute rejection by $\mathrm{NF} / \mathrm{RO}$ membranes $[9,20,22-23]$. In fact, colloidal fouling resulted in a severe drop in conductivity and sodium rejection by the NF270 membrane (Figure 6), which is in good agreement with previous studies $[18,20-22,24,26-28,48]$. The considerable increase in boron concentration at the 
membrane surface coupled with the decline in permeate flux resulted in a significant decrease in boron rejection by the fouled membranes as observed in Figure 5. It is noteworthy that cake-enhanced concentration polarisation could occur and reduce boron rejection under either low or high $\mathrm{pH}$ conditions. However, because the boron rejection efficiency of the virgin NF270 membrane was negligible at low pH conditions, the effect of cake-enhanced concentration polarisation on boron rejection was not apparent at this low $\mathrm{pH}$ condition. The occurrence and influence of cake-enhanced concentration polarisation were further confirmed by the lower sodium rejection by the colloidal silica fouled membrane observed in Figure 6 .

The humic acid fouling layer could significantly increase boron rejection by both NF270 and BW30 membrane at all $\mathrm{pH}$ values within the investigated $\mathrm{pH}$ range (Figure 5). This phenomenon was more apparent at the NF270 membrane. At pH lower than 9, boron rejections by the humic acid fouled NF270 and BW30 membranes were 30\% and 15\% higher than for the virgin membranes, respectively. It was found that size exclusion is a dominant removal mechanism for the neutral boric acid species [42]. The data reported in Figure 5 implied that the adsorption of humic acid on the membrane surface would enhance both size exclusion and charge repulsion mechanisms. The enhancement of size exclusion might be attributed to the phenomenon where the 'hot spots' on membrane surface with high local flux and low salt rejection were plugged by humic material [27, 45], which resulted in the increase in the steric-hindrance impact. For the BW30 membrane, the increase in size exclusion could also be driven by the clogged valleys on the rough surface of this membrane. In addition, the greatly negative charge of the humic layer resulted in a significant increase in boron rejection by charge repulsion mechanism under high $\mathrm{pH}$ conditions. The effect of the humic acid fouling layer to improve solute rejection was further confirmed by the higher conductivity and sodium rejection obtained by the humic acid fouled NF270 membrane as illustrated in Figure 6. This result is also consistent with several previous studies [7, 14, 49]. Cakeenhanced concentration polarisation might occur and decrease boron rejection by the humic acid fouled NF270 and BW30 membranes. However, the decrease in boron rejection caused by this effect was probably compensated by the significant increase in boron rejection caused by the 'hot spots' clogging and membrane surface charge increasing as discussed above [27, 45]. 


\section{Conclusion}

The impacts of four different model foulants on the performance of NF/RO membranes were investigated in this study. Organic foulants (humic acid and sodium alginate) caused the most severe drop in permeates flux and followed by colloidal silica and $\mathrm{CaSO}_{4}$ scaling. Various extents of flux decline caused by different model foulants implied different fouling mechanisms involved. All membrane fouling experiments investigated in this study, including with different foulants and membranes used, appeared to be subjected to the cakeenhanced concentration polarisation phenomenon which not only caused severe permeate flux decline, but also decreased the rejection efficiency of boron and inorganic salts. In addition, the fouling layer could also play the role of a physical barrier that inhibited the impact of solution $\mathrm{pH}$ changes on membrane surface charged properties. Consequently, the effect of high solution $\mathrm{pH}$ to increase membrane surface negative charge that encouraged boron rejection was inhibited. In addition to cake-enhanced concentration polarisation, boron rejection efficiency could also be reduced by the membrane charge neutralisation effect of the fouling layer, particularly of colloidal silica and $\mathrm{CaSO}_{4}$ scaling layer. In contrast, boron rejection could be improved by the adsorption of humic acid on the membrane surface because of the highly negatively charge property of the humic substance.

\section{Acknowledgements}

Tony Nicholas, Laurent Devriendt and Helen Price are thanked for their technical advice regarding ICP-MS analysis. Alex Simon is thanked for the measurement of the membrane zeta potential. Dow FilmTec (Minneapolis, MN, USA) is gratefully acknowledged for the donation of membrane samples to this research. 


\section{References}

1. N. Hilal, G.J. Kim, and C. Somerfield, Boron removal from saline water: A comprehensive review, Desalination 273 (2011) 23-35.

2. K.L. Tu, L.D. Nghiem, and A.R. Chivas, Boron removal by reverse osmosis membranes in seawater desalination applications, Separation and Purification Technology 75 (2010) 87-101.

3. E. Huertas, M. Herzberg, G. Oron, and M. Elimelech, Influence of biofouling on boron removal by nanofiltration and reverse osmosis membranes, Journal of Membrane Science 318 (2008) 264-270.

4. H.-J. Oh, T.-M. Hwang, and S. Lee, A simplified simulation model of RO systems for seawater desalination, Desalination 238 (2009) 128-139.

5. M.F.A. Goosen, S.S. Sablani, H. Ai-Hinai, S. Ai-Obeidani, R. Al-Belushi, and D. Jackson, Fouling of reverse osmosis and ultrafiltration membranes: A critical review, Separation Science and Technology 39 (2004) 2261-2297.

6. Y. Kaiya, Y. Itoh, K. Fujita, and S. Takizawa, Study on fouling materials in the membrane treatment process for potable water, Desalination 106 (1996) 71-77.

7. C.Y. Tang, Y.-N. Kwon, and J.O. Leckie, Fouling of reverse osmosis and nanofiltration membranes by humic acid--Effects of solution composition and hydrodynamic conditions, Journal of Membrane Science 290 (2007) 86-94.

8. L.D. Nghiem and P.J. Coleman, NF/RO filtration of the hydrophobic ionogenic compound triclosan: Transport mechanisms and the influence of membrane fouling, Separation and Purification Technology 62 (2008) 709-716.

9. Q. Li and M. Elimelech, Synergistic effects in combined fouling of a loose nanofiltration membrane by colloidal materials and natural organic matter, Journal of Membrane Science 278 (2006) 72-82.

10. S. Hong and M. Elimelech, Chemical and physical aspects of natural organic matter (NOM) fouling of nanofiltration membranes, Journal of Membrane Science 132 (1997) 159-181.

11. J.A. Nilson and F.A. DiGiano, Influence of NOM composition on nanofiltration, Journal / American Water Works Association 88 (1996) 53-66.

12. Q. Li, Z. Xu, and I. Pinnau, Fouling of reverse osmosis membranes by biopolymers in wastewater secondary effluent: Role of membrane surface properties and initial permeate flux, Journal of Membrane Science 290 (2007) 173-181.

13. L.D. Nghiem and S. Hawkes, Effects of membrane fouling on the nanofiltration of trace organic contaminants, Desalination 236 (2009) 273-281.

14. A.E. Childress and M. Elimelech, Effect of solution chemistry on the surface charge of polymeric reverse osmosis and nanofiltration membranes, Journal of Membrane Science 119 (1996) 253-268.

15. S.-H. Yoon, C.-H. Lee, K.-J. Kim, and A.G. Fane, Effect of calcium ion on the fouling of nanofilter by humic acid in drinking water production, Water Research 32 (1998) 2180-2186. 
16. A.I. Schäfer, A.G. Fane, and T.D. Waite, Nanofiltration of natural organic matter: Removal, fouling and the influence of multivalent ions, Desalination 118 (1998) 109122.

17. C. Jarusutthirak, S. Mattaraj, and R. Jiraratananon, Influence of inorganic scalants and natural organic matter on nanofiltration membrane fouling, Journal of Membrane Science 287 (2007) 138-145.

18. H.Y. Ng and M. Elimelech, Influence of colloidal fouling on rejection of trace organic contaminants by reverse osmosis, Journal of Membrane Science 244 (2004) 215-226.

19. P. Xu, J.E. Drewes, T.-U. Kim, C. Bellona, and G. Amy, Effect of membrane fouling on transport of organic contaminants in NF/RO membrane applications, Journal of Membrane Science 279 (2006) 165-175.

20. S. Lee, J. Cho, and M. Elimelech, Influence of colloidal fouling and feed water recovery on salt rejection of RO and NF membranes, Desalination 160 (2004) 1-12.

21. R.D. Cohen and R.F. Probstein, Colloidal fouling of reverse osmosis membranes, Journal of Colloid and Interface Science 114 (1986) 194-207.

22. E.M.V. Hoek, A.S. Kim, and M. Elimelech, Influence of crossflow membrane filter geometry and shear rate on colloidal fouling in reverse osmosis and nanofiltration separations, Environmental Engineering Science 19 (2002) 357-372.

23. E.M.V. Hoek and M. Elimelech, Cake-Enhanced Concentration Polarization: A New Fouling Mechanism for Salt-Rejecting Membranes, Environmental Science and Technology 37 (2003) 5581-5588.

24. S. Lee, J. Cho, and M. Elimelech, Combined influence of natural organic matter (NOM) and colloidal particles on nanofiltration membrane fouling, Journal of Membrane Science 262 (2005) 27-41.

25. J.A. Brant and A.E. Childress, Membrane-colloid interactions: Comparison of extended DLVO predictions with AFM force measurements, Environmental Engineering Science 19 (2002) 413-427.

26. X. Zhu and M. Elimelech, Colloidal fouling of reverse osmosis membranes: Measurements and fouling mechanisms, Environmental Science and Technology 31 (1997) 3654-3662.

27. E.M. Vrijenhoek, S. Hong, and M. Elimelech, Influence of membrane surface properties on initial rate of colloidal fouling of reverse osmosis and nanofiltration membranes, Journal of Membrane Science 188 (2001) 115-128.

28. K. Boussu, A. Belpaire, A. Volodin, C. Van Haesendonck, P. Van der Meeren, C. Vandecasteele, and B. Van der Bruggen, Influence of membrane and colloid characteristics on fouling of nanofiltration membranes, Journal of Membrane Science 289 (2007) 220-230.

29. S. Lee, J. Kim, and C.-H. Lee, Analysis of CaSO4 scale formation mechanism in various nanofiltration modules, Journal of Membrane Science 163 (1999) 63-74.

30. J. Gilron and D. Hasson, Calcium sulphate fouling of reverse osmosis membranes: Flux decline mechanism, Chemical Engineering Science 42 (1987) 2351-2360. 
31. A.G. Pervov, Scale formation prognosis and cleaning procedure schedules in reverse osmosis systems operation, Desalination 83 (1991) 77-118.

32. C. Bellona and J.E. Drewes, The role of membrane surface charge and solute physicochemical properties in the rejection of organic acids by NF membranes, Journal of Membrane Science 249 (2005) 227-234.

33. P. Argust, Distribution of boron in the environment, Biological Trace Element Research 66 (1998) 131-143.

34. F. Fairbrother and H. Mastin, Studies in electro-endosmosis, Journal of the Chemical Society 125 (1924) 2319-2330.

35. L.D. Nghiem, A.I. Schäfer, and M. Elimelech, Removal of Natural Hormones by Nanofiltration Membranes: Measurement, Modeling and Mechanisms, Environmental Science and Technology 38 (2004) 1888-1896.

36. J.R. McCutcheon and M. Elimelech, Influence of membrane support layer hydrophobicity on water flux in osmotically driven membrane processes, Journal of Membrane Science 318 (2008) 458-466.

37. A.I. Schäfer, A. Pihlajamäki, A.G. Fane, T.D. Waite, and M. Nyström, Natural organic matter removal by nanofiltration: effects of solution chemistry on retention of low molar mass acids versus bulk organic matter, Journal of Membrane Science 242 (2004) 73-85.

38. S. Lee and M. Elimelech, Relating organic fouling of reverse osmosis membranes to intermolecular adhesion forces, Environmental Science and Technology 40 (2006) 980-987.

39. M. Beyer, B. Lohrengel, and L.D. Nghiem, Membrane fouling and chemical cleaning in water recycling applications, Desalination 250 (2010) 977-981.

40. W.S. Ang, S. Lee, and M. Elimelech, Chemical and physical aspects of cleaning of organic-fouled reverse osmosis membranes, Journal of Membrane Science 272 (2006) 198-210.

41. C. Park, Y.H. Lee, S. Lee, and S. Hong, Effect of cake layer structure on colloidal fouling in reverse osmosis membranes, Desalination 220 (2008) 335-344.

42. K.L. Tu, L.D. Nghiem, and A.R. Chivas, Coupling effects of feed solution pH and ionic strength on the rejection of boron by NF/RO membranes, Chemical Engineering Journal 168 (2011) 700-706.

43. M.H. Oo and L. Song, Effect of $\mathrm{pH}$ and ionic strength on boron removal by RO membranes, Desalination 246 (2009) 605-612.

44. A. Sagiv and R. Semiat, Analysis of parameters affecting boron permeation through reverse osmosis membranes, Journal of Membrane Science 243 (2004) 79-87.

45. C.Y. Tang, Y.-N. Kwon, and J.O. Leckie, Characterization of Humic Acid Fouled Reverse Osmosis and Nanofiltration Membranes by Transmission Electron Microscopy and Streaming Potential Measurements, Environmental Science \& Technology 41 (2006) 942-949. 
46. L.D. Nghiem and S. Hawkes, Effects of membrane fouling on the nanofiltration of pharmaceutically active compounds (PhACs), Separation and Purification Technology 57 (2007) 176-184.

47. A.R.D. Verliefde, E.R. Cornelissen, S.G.J. Heijman, I. Petrinic, T. Luxbacher, G.L. Amy, B. Van der Bruggen, and J.C. van Dijk, Influence of membrane fouling by (pretreated) surface water on rejection of pharmaceutically active compounds (PhACs) by nanofiltration membranes, Journal of Membrane Science 330 (2009) 90103.

48. S.G. Yiantsios and A.J. Karabelas, The effect of colloid stability on membrane fouling, Desalination 118 (1998) 143-152.

49. J. Cho, G. Amy, and J. Pellegrino, Membrane filtration of natural organic matter: comparison of flux decline, NOM rejection, and foulants during filtration with three UF membranes, Desalination 127 (2000) 283-298. 